\section{Commentary: How can you mend a broken heart: Mechanical valve leaflet fracture}

\author{
Parth M. Patel, MD, and Edward P. Chen, MD
}

Helgeland $^{1}$ has reported the fourth known case of On-X mechanical valve leaflet fracture with embolization and only the second patient to have survived this complication. Acute massive prosthetic mitral valve regurgitation carries high mortality, and Helgeland ${ }^{1}$ should first be commended on their successful treatment of this patient. ${ }^{2}$ Although older mechanical valves had a greater propensity of valve fracture and embolization, newer generation models can also be at risk for this complication, as seen by this report and others. ${ }^{3-6}$

Patients presenting with acute mitral regurgitation will often be in cardiogenic shock. ${ }^{7}$ The initial management should include stabilization of the hemodynamics to optimize end organ perfusion and appropriate intervention to correct the mitral regurgitation. ${ }^{7}$ In the setting of a previous mechanical valve implant, prosthetic valve thrombosis has often represented a common etiology of this condition. Preoperative management can include elective intubation, depending on the severity of the pulmonary edema. Patient hemodynamics can be supported by afterload reduction and inotropic medication but might require mechanical circulatory support in the form of an intra-aortic balloon pump, a percutaneous ventricular assist device, or, even, extracorporeal membranous oxygenation. ${ }^{7}$ Ultimately, patients will typically require reoperative mitral valve replacement, and the timing of surgical intervention will depend on the presence and severity of heart failure,

\footnotetext{
From the Division of Cardiothoracic Surgery, Department of Surgery, Emory University School of Medicine, Atlanta, Ga.

Disclosures: The authors reported no conflicts of interest.

The Journal policy requires editors and reviewers to disclose conflicts of interest and to decline handling or reviewing manuscripts for which they may have a conflict of interest. The editors and reviewers of this article have no conflicts of interest.

Received for publication June 17, 2020; revisions received June 17, 2020; accepted for publication June 19, 2020; available ahead of print June 30, 2020.

Address for reprints: Edward P. Chen, MD, Division of Cardiothoracic Surgery, Department of Surgery, Emory University School of Medicine, 5565 Peachtree Dunwoody Rd, Suite 200, Atlanta, GA 30342 (E-mail: edward.p.chen@emory. edu).

JTCVS Techniques 2020;3:144-5

2666-2507

Copyright (c) 2020 The Authors. Published by Elsevier Inc. on behalf of The American Association for Thoracic Surgery. This is an open access article under the CC BY-NCND license (http://creativecommons.org/licenses/by-nc-nd/4.0/).

https://doi.org/10.1016/j.xjtc.2020.06.043
}

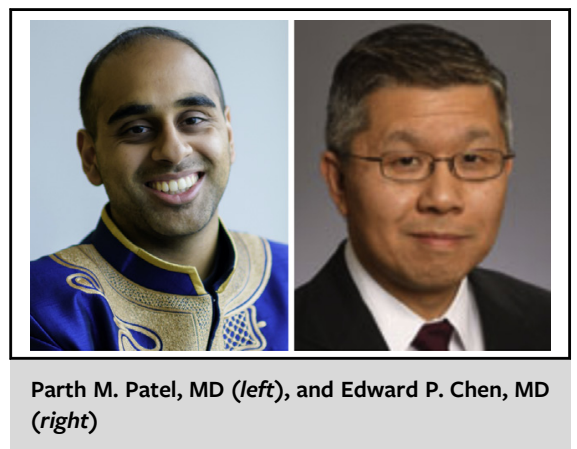

\author{
CENTRAL MESSAGE \\ A rapid and accurate diagnosis, \\ along with appropriate manage- \\ ment, offers the best chance for \\ optimal patient outcomes in \\ mechanical prosthetic valve \\ leaflet fracture.
}

severity of hemodynamic compromise, and the patient's responsiveness to the initial stabilizing measures.

Helgeland $^{1}$ appropriately highlighted that rapid diagnosis and treatment are critical to patient survival in the setting of leaflet fracture. As outlined in the report, the imaging modalities essential for the diagnosis of leaflet fracture include transesophageal echocardiography and noncontrast-enhanced computed tomography. The use of transesophageal echocardiography will allow the identification of the nature and severity of the mitral regurgitation, and non-contrast-enhanced computed tomography will be necessary to identify the location of the embolized portion of the prosthetic valve. ${ }^{7}$ Plain roentgenograms, although an appropriate initial test on patient presentation, will not be sufficient to identify the presence of a fractured leaflet or the location of the embolized fragment. Similarly, the use of fluoroscopy, as in this case, could delay the diagnosis.

The potential benefit of retrieving an embolized fractured leaflet and the appropriate timing of such an intervention have continued to be debated. ${ }^{4,8}$ The distal location of an embolus and patient symptoms, including signs of malperfusion, should be used as clinical guides to determine the urgency of retrieval. In this case, Helgeland ${ }^{1}$ wisely chose to first address the patient's hemodynamic compromise with redo-mitral valve replacement before performing further diagnostic studies, followed by retrieval of the embolized piece during a second operation.

With this case report, Helgeland ${ }^{1}$ has brought to light an extremely, rare but important, complication of modern 
prosthetic valves. Leaflet fracture can occur at any time after prosthetic valve implantation and must remain a part of the differential diagnosis for acute prosthetic valve mitral regurgitation. $^{4-6}$ Transesophageal echocardiography and noncontrast-enhanced computed tomography are necessary tools for an accurate diagnosis, and the appropriate management is similar to that for acute mitral regurgitation secondary to valve thrombosis. Given the mortality of $50 \%$ in the reported data, a rapid, and accurate diagnosis, as well as appropriate initial management, offers the best chance for optimal patient outcomes. ${ }^{4-6}$

\section{References}

1. Helgeland E. Leaflet fracture and embolization from an On-X mechanical mitral valve. J Thorac Cardiovasc Surg Tech. 2020;3:140-3.
2. Cooper DK, Sturridge MF. Acute massive mitral regurgitation from prosthetic valve dysfunction. Br Heart J. 1976;38:701-5.

3. Blot WJ, Ibrahim MA, Ivey TD, Acheson DE, Brookmeyer R, Weyman A, et al Twenty-five-year experience with the Björk-Shiley convexoconcave heart valve: a continuing clinical concern. Circulation. 2005;111:2850-7.

4. Amorós Rivera C, López Rodríguez FJ, Arnáiz García ME, Arévelo Abascal RM, Barral Varela AM, López Tatis MM, et al. Survival after mitral valve replacement for leaflet escape in a contemporary on-X mechanical valve. Ann Thorac Surg. 2019;108:e307-9.

5. Göbel N, Tanriverdi S, Nagib R, Franke UFW. Cardiogenic shock due to leaflet migration of On-X® aortic mechanical prosthesis. Ann Thorac Surg. February 27, 2020 [Epub ahead of print].

6. Kageyama S, Yoshioka D, Kawasumi R, Ohashi T. Sudden haemodynamic collapse caused by leaflet escape of the contemporary On-X mechanical valve. Eur J Cardiothorac Surg. 2018;54:608.

7. Maheshwari V, Barr B, Srivastava M. Acute valvular heart disease. Cardiol Clin 2018;36:115-27.

8. Pawale A, El-Eshmawi A, Tang GH, Ellozy SH, Anyanwu AC. Emergency valve re-replacement for embolization of prosthetic mitral valve disc during catheterization procedure. Ann Thorac Surg. 2013;95:1784-7. 